\title{
A RNA-Seq Analysis of the Response of Photosynthetic System to Low Nitrogen Supply in Maize Leaf
}

\author{
Xiaohuan Mu, Qinwu Chen, Fanjun Chen, Lixing Yuan (10) and Guohua Mi * \\ Department of Plant Nutrition, China Agricultural University, Beijing 100193, China; \\ muxiaohuan@cau.edu.cn (X.M.); chenqw@cau.edu.cn (Q.C.); caucfj@cau.edu.cn (F.C.); \\ yuanlixing@cau.edu.cn (L.Y.) \\ * Correspondence: miguohua@cau.edu.cn; Tel.: +86-10-6273-4454
}

Received: 28 October 2017; Accepted: 30 November 2017; Published: 5 December 2017

\begin{abstract}
Nitrogen is a major limiting factor for crop productivity. The relationship between photosynthesis and nitrogen nutrition has been widely studied. However, the molecular response of leaf photosynthesis to low nitrogen supply in crops is less clear. In this study, RNA sequencing technology (RNA-Seq) was used to investigate the gene expressions related to photosynthesis in maize in response to low nitrogen supply. It was found that low nitrogen supply down-regulated the expression of genes involved in photosystem I (PSI) and photosystem II (PSII). Thus, low nitrogen supply down-regulated the expression of genes related to the antenna system, reduced light absorption, light transport, and electron transport. Correspondingly, the parameters related to chlorophyll fluorescence were very sensitive to nitrogen deficiency. Under low nitrogen supply, leaf chlorophyll content, actual quantum yield of PSII photochemistry, photochemical quenching, and electron transport rate, were reduced. However, the thermal diffusion and chlorophyll fluorescence were increased. RNA-Seq was used to analyze the genes involved in the response of leaf photosynthesis to low nitrogen supply in maize. These results highlight the possibility of utilizing chlorophyll fluorescence parameters, and the related genes, as indicators for plant nitrogen nutrition. This could lead to the development of new tools to make precise nitrogen fertilizer recommendations and select nitrogen-efficient genotypes.
\end{abstract}

Keywords: chlorophyll fluorescence; electron transport rate; nitrogen; photosynthesis; PSI; PSII; maize

\section{Introduction}

Nitrogen $(\mathrm{N})$ is a fundamental constituent of many cell components such as amino acids, proteins, cell walls, membranes and nucleic acids. Nitrogen deficiency reduces plant growth and development, photosynthesis, leaf area, and ultimately limits plant productivity [1-4]. For a sustainable crop production system, there is a requirement to reduce nitrogen fertilizer input, and increase nitrogen use efficiency. This may be achieved by understanding the relationship between $\mathrm{N}$ nutrition and the photosynthetic rate in the leaf $[5,6]$.

Photosynthesis is a biological process whereby the sun's energy is captured and stored in a series of events that convert the pure energy of light into the biochemical energy needed to power life [7]. Photosynthesis includes two reactions: light reactions and carbon reduction reactions [7]. Light reactions take place on thylakoid membranes. Thylakoid membranes mainly include four membrane protein complexes: photosystem I (PSI), photosystem II (PSII), cytochrome $b_{6} f$ complex $\left(\right.$ Cyt $\left.b_{6} f\right)$, and adenosine triphosphate (ATP) synthase. Carbon reduction reactions take place in the stroma of chloroplast. Ribulose-1,5-bisphosphate carboxylase (Rubisco), phosphoenolpyruvate carboxylase 
(PEPc) and pyruvate orthophosphate dikinase (PPDK) are the key enzymes for $\mathrm{C}_{4}$ plants. Light is absorbed by pigments (mainly chlorophylls) associated with two photosystems: PSI and PSII. For light energy to be stored by photosynthesis, it is channeled by a number of different processes including photochemistry, heat dissipation (including photo-protective heat dissipation and other heat dissipation), and chlorophyll fluorescence [8]. Chlorophyll fluorescence is an important parameter in representing changes in the growth environment and function of the photosynthetic process [8]. For example, in rice, nitrogen deficiency decreases the actual quantum yield of PSII photochemistry $\left(\Phi_{\mathrm{PSII}}\right)$, the maximal efficiency of PSII photochemistry $(F \mathrm{v} / F \mathrm{~m})$, excitation energy capture efficiency of PSII $\left(F v^{\prime} / F m^{\prime}\right)$, as well as the electron transport rate (ETR) [9].

Photosynthesis depends on many physiological and biochemical processes such as stomatal conductance, intercellular $\mathrm{CO}_{2}$ concentration, photochemical capacity of PSII, and contents and activities of carbon fixation enzymes [10]. Photosynthesis has a positive relationship with leaf nitrogen $[3,5,11,12]$. This is because about $70 \%$ of leaf nitrogen is located in the chloroplast $[11,13]$. Nitrogen deficiency reduces the content of chlorophyll, Cyt $f$, coupling factor, $\mathrm{N}$ content of thylakoid in light reactions, as well as the ETR $[5,14]$. Nitrogen deficiency also decreased the content and/or activity of Rubisco, PEPc and PPDK $[3,5,11,12]$. The decreased photosynthesis in nitrogen deficiency may be caused by different reasons in different plants under different conditions. For example, decreased photosynthesis in low nitrogen was mainly associated with lower stomatal conductance in sorghum under outdoor pot-culture conditions [10]. At light saturation, the decline in photosynthesis in nitrogen deficiency was mainly caused by the limitation of reduced mesophyllic activity, rather than by stomatal limitation in sunflowers [15]. Nitrogen deficiency repressed SPSII, causing decreased ETR to match the decreased requirements for ATP and triphosphopyridine nucleotide (NADPH) in the case of decreased $\mathrm{CO}_{2}$ assimilation capacity in maize grown outdoors [16].

Maize is an important crop worldwide with multiple purposes such as food, fodder, and bioenergy. Although the relationship between nitrogen deficiency and photosynthesis has been widely studied in maize, less is known about the molecular mechanism underlying the response of the photosynthetic system in maize to nitrogen deficiency. Such information is important not only for improving photosynthesis performance under insufficient nitrogen supply via gene manipulation, but also for the development of potential molecular tools for the diagnosis of plant nitrogen nutrition status. This could be used in both the selection of nitrogen-efficient genotypes and precision nitrogen fertilizer management. In the present study, using an integrated approach including physiological analysis and RNA sequencing (RNA-Seq), we aimed to explore the genes related to photosynthesis under nitrogen deficiency, especially those related to light reactions.

\section{Results}

\subsection{Effect of Nitrogen Supply on Biomass}

Nitrogen supply has a significant effect on biomass and nitrogen accumulation. Low nitrogen treatment reduced total biomass by $15 \%$, and shoot biomass by $25 \%$ (Table 1 ). However, low nitrogen treatment increased the root-shoot ratio by about two-thirds compared with the high nitrogen treatment, indicating that nitrogen-starved plants allocated more biomass to the root. Total nitrogen accumulation, as well as shoot nitrogen accumulation, in low nitrogen plants were reduced by $74 \%$ and $77 \%$, respectively (Table 1 ). 
Table 1. Effect of nitrogen supply on biomass and nitrogen accumulation in maize plants at the V6 stage.

\begin{tabular}{|c|c|c|c|c|c|}
\hline \multirow{2}{*}{ N Treatment } & Total Biomass & Shoot Biomass & Root-to-Shoot Ratio & Total N Content & Shoot N Content \\
\hline & \multicolumn{2}{|c|}{$\left(\mathrm{g} \cdot\right.$ plant $\left.^{-1}\right)$} & \multicolumn{3}{|c|}{$\left(\mathrm{mg} \cdot\right.$ plant $\left.^{-1}\right)$} \\
\hline High Nitrogen & $2.74 \mathrm{a}$ & $2.05 \mathrm{a}$ & $0.34 \mathrm{~b}$ & $132.26 \mathrm{a}$ & $101.33 \mathrm{a}$ \\
\hline Low Nitrogen & $2.32 \mathrm{~b}$ & $1.54 \mathrm{~b}$ & $0.51 \mathrm{a}$ & $33.89 \mathrm{~b}$ & $23.48 \mathrm{~b}$ \\
\hline
\end{tabular}

Note: Different letters in the same column indicate significant differences between nitrogen treatments $(p<0.05)$.

\subsection{Effect of Nitrogen Supply on Leaf Photosynthesis}

As expected, low nitrogen significantly reduced the leaf area (Figure 1a). Nitrogen supply has a significant effect on specific leaf nitrogen (SLN) and the photosynthetic rate (Figure 1b). SLN is lower $(82 \%)$ in low nitrogen treatment compared with high nitrogen treatment. The photosynthetic rate in low nitrogen stress is reduced by $83 \%$ compared with high nitrogen treatment. The chlorophyll (Chl), chlorophyll a, and chlorophyll b concentration are lower $(67 \%, 69 \%$ and $59 \%$ respectively) in low nitrogen plants compared with high nitrogen plants (Figure 2). The ratio of $\mathrm{Chl}$ to $\mathrm{N}$ was $31 \%$ higher in low nitrogen treatment compared with high nitrogen treatment.
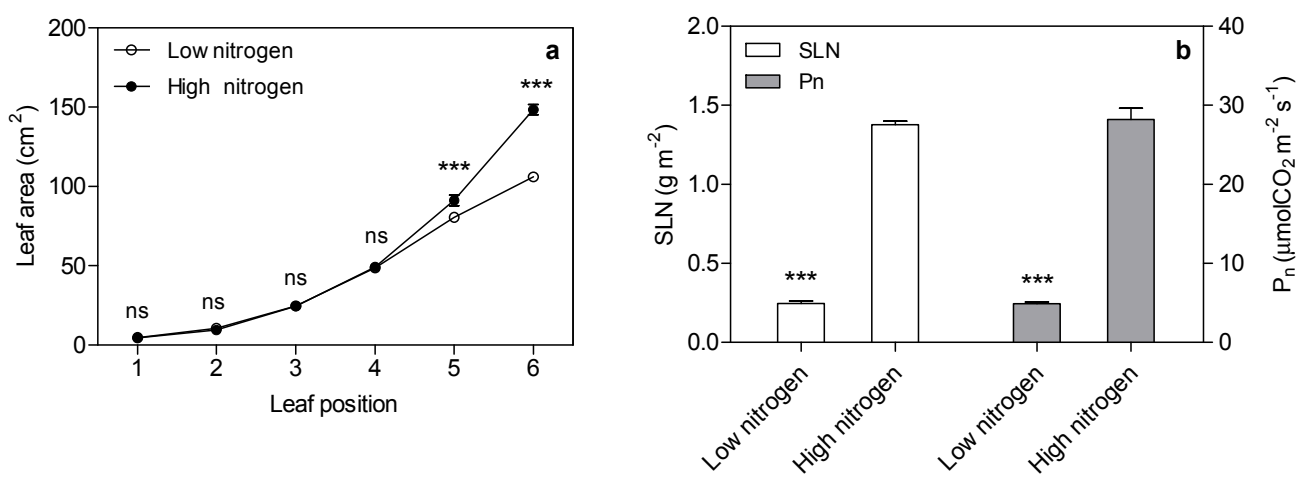

Figure 1. Effect of nitrogen supply on leaf area (a), specific leaf nitrogen (SLN) and photosynthetic rate $\left(p_{\mathrm{n}}\right)$ of the sixth leaf in maize (b). Bars denote the standard error (SE) of the mean. ns: not significant $(p>0.05) ;{ }^{* * *}$ : significant at $p<0.001$.

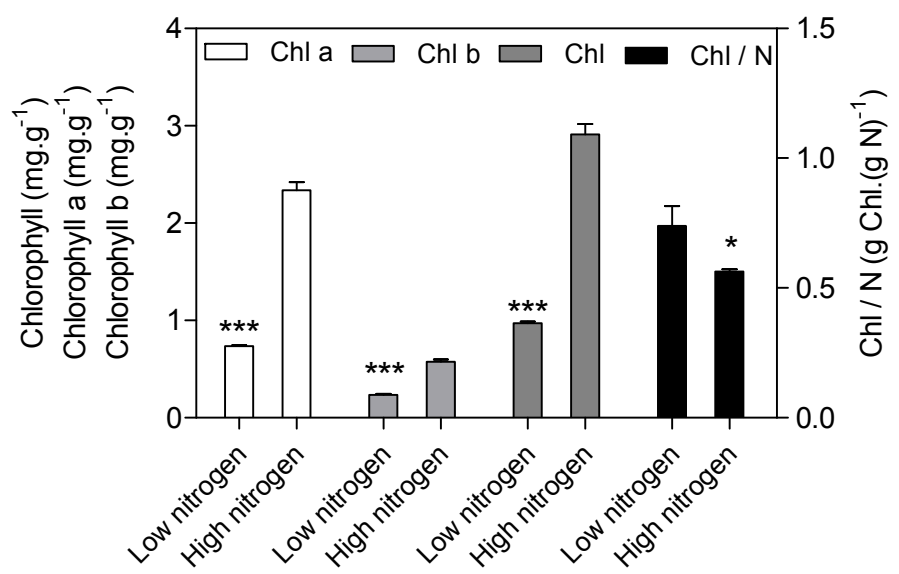

Figure 2. Effect of nitrogen supply on chlorophyll (Chl) concentration and $\mathrm{Chl} / \mathrm{N}$ in the sixth leaf of maize. High nitrogen: $4 \mathrm{mM} \mathrm{Ca}\left(\mathrm{NO}_{3}\right)_{2}$; Low nitrogen: $40 \mu \mathrm{M} \mathrm{Ca}\left(\mathrm{NO}_{3}\right)_{2}$. Bars denote the SE of the mean. ns: not significant $(p>0.05){ }^{*}{ }^{* *}$ and ${ }^{* * *}$ : significant at $p<0.05,0.01$ and 0.001 , respectively. 


\subsection{Low Nitrogen-Induced Gene Expression in the Leaf}

We used RNA-Seq analysis of the mature tissue of an expanding leaf in order to unravel the molecular mechanisms underlying the response of the photosynthetic system to low nitrogen supply. A total of more than 33 million high quality 125-bp paired-end reads were generated by RNA-Seq for each treatment. Comparisons of two biological replicates showed that expression values were highly correlated (average $R^{2}=0.9288$, Figure S1).

Setting thresholds of a False Discovery Rate of less than 0.05 and a two-fold change in expression, we found 1625 differentially expressed genes (DEGs) in low nitrogen compared with high nitrogen treatment. Of these genes, 928 were downregulated whilst 697 upregulated (Supplemental Table S1). The identified genes were subjected to gene ontology term (GO) enrichment analysis. The downregulated DEGs were mainly involved in photosynthesis, homeostatic processes, regulation of nitrogen metabolism, redox activity, and response to abiotic stimulus (Figure 3a; Supplemental Table S2). The upregulated DEGs were mainly involved in cellular polysaccharide processes, carbohydrate biosynthesis processes and cellular metabolic processes (Figure 3b; Supplemental Table S2). Using MapMan analysis, it is further identified that most downregulated DEGs were involved in photosynthesis processes, TCA cycling, and nitrogen assimilation processes (Figure 4; Supplemental Table S3). The upregulated DEGs were mainly associated with lipids, the cell wall, and secondary metabolism processes (Figure 4; Supplemental Table S3).

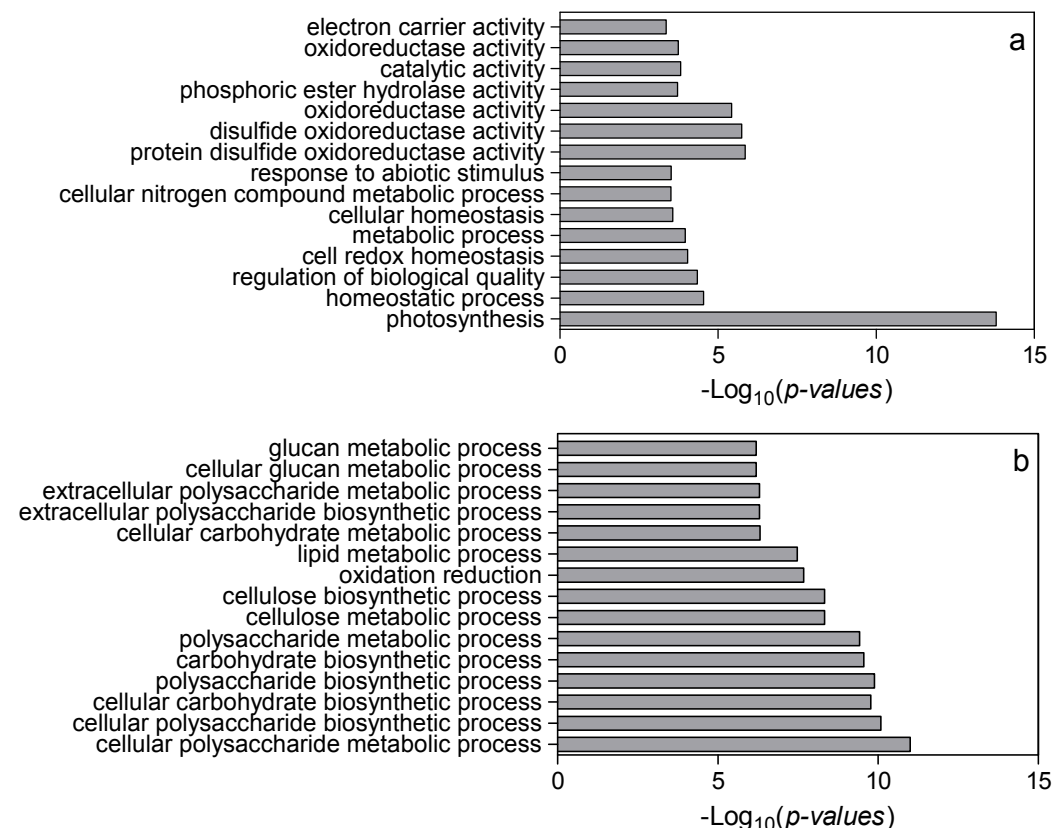

Figure 3. Significantly enriched gene ontology (GO) terms in downregulated (a) and upregulated (b) differentially expressed genes in low nitrogen versus high nitrogen in the sixth leaf. High nitrogen: $4 \mathrm{mM} \mathrm{Ca}\left(\mathrm{NO}_{3}\right)_{2}$; low nitrogen: $40 \mu \mathrm{M} \mathrm{Ca}\left(\mathrm{NO}_{3}\right)_{2}$. After $\mathrm{GO}$ analysis, every significantly enriched GO term has a $p$-value. The smaller $p$-value, the more reliable GO result is.

The DEGs involved in photosynthesis were analyzed (Figure 5; Supplemental Table S4). Under low nitrogen supply, 11 DEGs encoding light harvesting complex II (LHCII) and three DEGs encoding LHCI were downregulated, 16 DEGs encoding PSII polypeptide subunits and 10 DEGs encoding PSI polypeptide subunits were downregulated, 3 DEGs encoding ATP synthase were downregulated, 1 DEG encoding ferredoxin reductase was downregulated, and 10 DEGs involved in Calvin cycle were downregulated. In those DEGs, GRMZM2G351977, GRMZM2G414192, GRMZM2G149428 and GRMZM2G092427 encoded components of PSII: $L h c b 1$, Lhcb2, Lhcb5, respectively. The genes GRMZM2G038519 and GRMZM2G072280 encoded components of PSI: Lhca1 and Lhca2, respectively. 


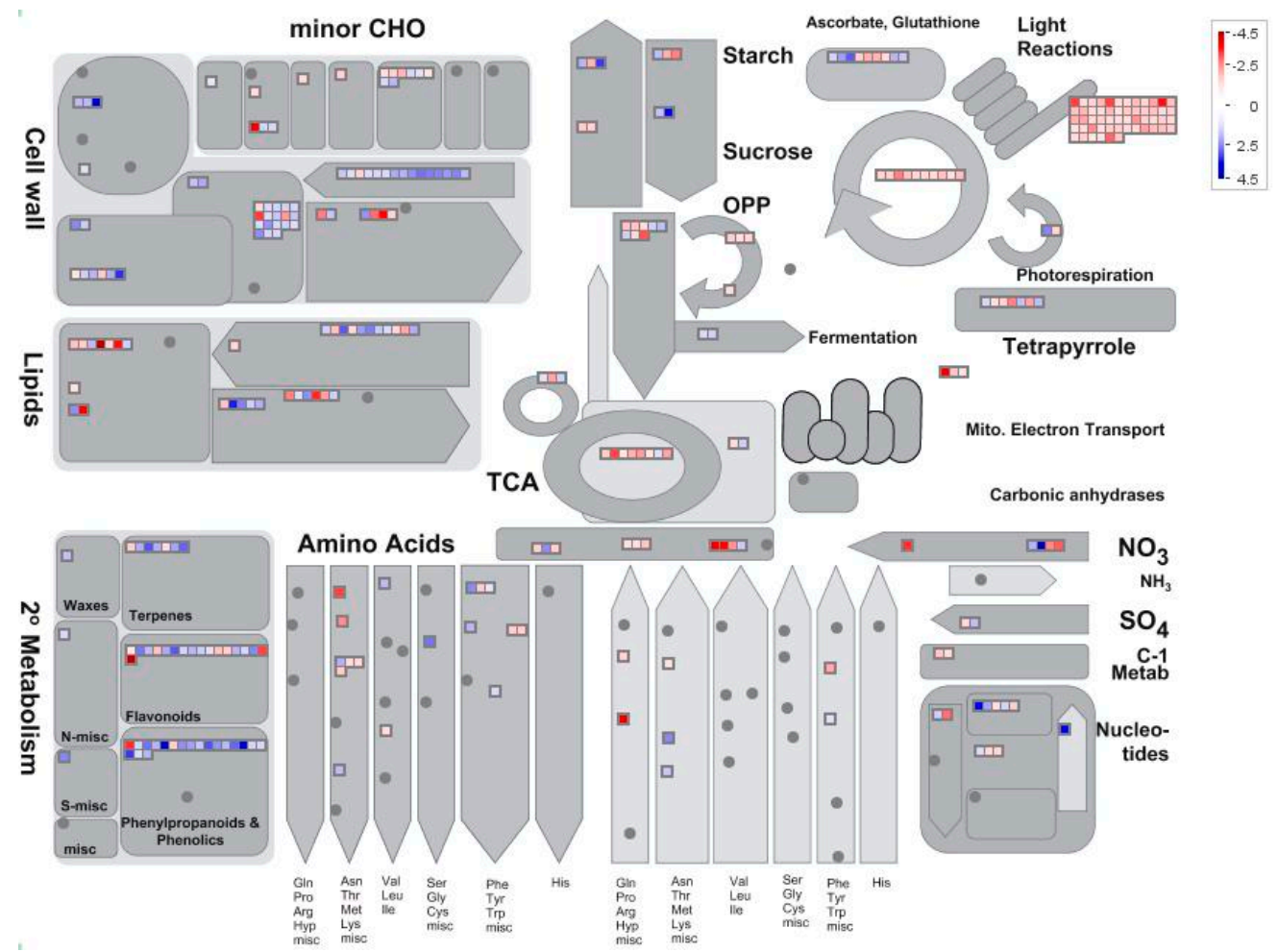

Figure 4. The distribution of different gene expressions involved in metabolism in maize leaf (low nitrogen versus high nitrogen). High nitrogen: $4 \mathrm{mM} \mathrm{Ca}\left(\mathrm{NO}_{3}\right)_{2}$; Low nitrogen: $40 \mu \mathrm{M} \mathrm{Ca}\left(\mathrm{NO}_{3}\right)_{2}$.
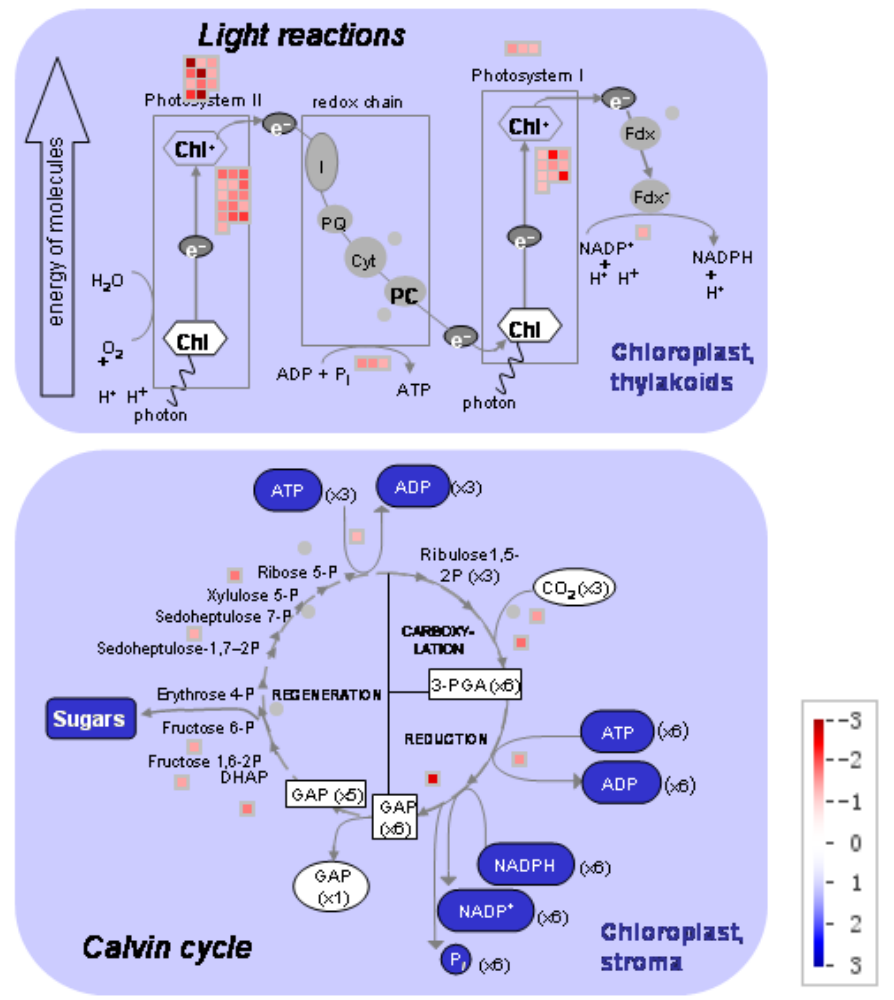

Figure 5. The distribution of different gene expressions related to photosynthesis in the maize leaf (low nitrogen versus high nitrogen). High nitrogen: $4 \mathrm{mM} \mathrm{Ca}\left(\mathrm{NO}_{3}\right)_{2}$; Low nitrogen: $40 \mu \mathrm{M} \mathrm{Ca}\left(\mathrm{NO}_{3}\right)_{2}$. 


\subsection{Effect of Low Nitrogen Supply on Leaf Chlorophyll Fluorescence}

Leaf chlorophyll fluorescence was analyzed to confirm the effect of low nitrogen supply on the light reaction system. Nitrogen supply has a great effect on chlorophyll fluorescence (Figure 6). The $F \mathrm{v} / F \mathrm{~m}$ and $F \mathrm{v}^{\prime} / F \mathrm{~m}^{\prime}$ were $6.6 \%$ and $20.4 \%$ lower in low-nitrogen plants compared with high nitrogen plants, respectively (Figure 6a). The actual quantum yield of PSII photochemistry ( $\Phi_{\text {PSII }}$ ) was reduced by $67.4 \%$ in low nitrogen treatment compared to high nitrogen treatment (Figure $6 \mathrm{~b}$ ). The electron transport rate (ETR) was $68.3 \%$ lower in low nitrogen plants than in high nitrogen plants (Figure $6 \mathrm{~b}$ ). The non-photochemical quenching $(q N)$ was $4.6 \%$ higher in low nitrogen treatment than in high nitrogen treatment (Figure 6c). The photochemical quenching $(q P)$ was lower $(49.6 \%)$ in low nitrogen treatment than in high nitrogen treatment. The $1-F \mathrm{v}^{\prime} / F \mathrm{~m}^{\prime}$ and $F \mathrm{v}^{\prime} / F \mathrm{~m}^{\prime} . *(1 q P)$ were higher $(18.3 \%$ and $10.3 \%$ respectively) in low nitrogen plants compared to high nitrogen plants (Figure $6 \mathrm{~d}$ ).
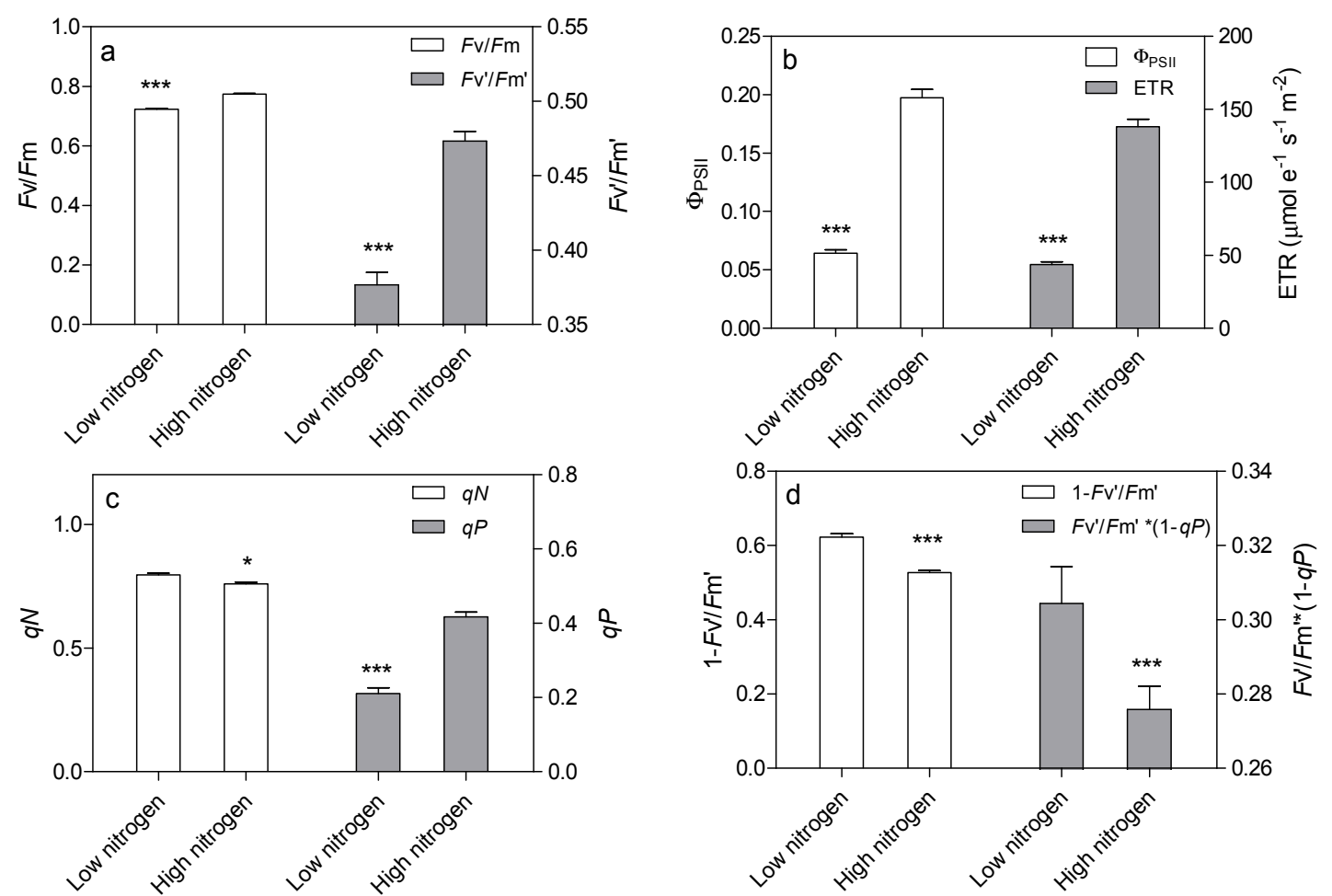

Figure 6. Effect of nitrogen supply on chlorophyll fluorescence parameters in the sixth leaf of maize. Effect of nitrogen supply on $F \mathrm{v} / F \mathrm{~m}$ and $F \mathrm{v}^{\prime} / F^{\prime}(\mathbf{a})$, on $\Phi_{\mathrm{PSII}}$ and ETR (b), on $q N$ and $q P(\mathbf{c})$, on $1-F_{v^{\prime}} / F \mathrm{~m}^{\prime}$ and $F_{\mathrm{v}^{\prime}} / F^{\prime} \mathrm{m}^{*}(1-q P)(\mathrm{d})$. High nitrogen: $4 \mathrm{mM} \mathrm{Ca}\left(\mathrm{NO}_{3}\right)_{2}$; Low nitrogen: $40 \mu \mathrm{M}$ $\mathrm{Ca}\left(\mathrm{NO}_{3}\right)_{2}$. Bars denote the SE of the mean. ns: not significant $(p>0.05) ;^{*},{ }^{* *}$ and ${ }^{* * *}$ : significant at $p<0.05,0.01$ and 0.001 , respectively.

\section{Discussion}

Increased photosynthesis with less input of land, water, nutrients, etc., is essential to sustainably meet global food and bioenergy demands $[17,18]$. New models have been proposed to increase the efficiency of light capture, light energy conversion, and carbon capture and conversion, possibly by rapidly developing genetic engineering technologies [18]. Photosynthesis has a close relationship with leaf nitrogen. In our study, leaf area was reduced by $22 \%$ in low nitrogen treatment. The photosynthetic rate in low nitrogen plants was $83 \%$ lower than in high nitrogen plants. Thus, the decrease in photosynthesis is the main reason for the decreasing biomass.

Nitrogen is a constituent of chlorophyll, photosynthetic enzymes (included Rubisco, PEPc and PPDK), and thylakoid membranes. These cellular features are located in chloroplast. About three-quarters of total nitrogen is found in chloroplast [11,13]. The optimal SLN for the maximum 
photosynthetic rate $\left(p_{\mathrm{n}}\right)$ is reported to be approximately $1.5 \mathrm{~g} \cdot \mathrm{m}^{-2}$ in field-grown maize [4,19-21]. In this research, the specific leaf nitrogen is only $0.25 \mathrm{~g} \cdot \mathrm{m}^{-2}$ in low nitrogen plants, $82 \%$ lower than that of the control treatment. This correlates well with the $83 \%$ reduction in the photosynthetic rate. This reduction in SLN is the result of the contribution of the different photosynthetic components mentioned above $[3,5,11]$. Here, we focused on the effect of nitrogen deficiency on the light reaction in photosynthesis.

Complexes PSII and PSI take part in light absorption, transport, and conversion. Photosystems are composed of two sections: (1) a reaction center devoted to the conversion of light energy into chemical energy; and (2) an antenna system that increases the capacity of light absorption and contributes to photoprotection [22]. The antenna system consists of many light-harvesting complexes (Lhc). Different members are associated with PSI (Lhca proteins) and PSII (Lhcb proteins) [23]. Over $60 \%$ of all the chlorophyll in plants is bound to light-harvesting complexes. Nitrogen deficiency leads to reduced total chlorophyll, chlorophyll $a$, and chlorophyll $b$ contents (Figure 2) $[3,5,11]$. The ratio of chlorophyll to leaf $\mathrm{N}$ could represent $\mathrm{N}$ allocation into chlorophyll [24]. The ratio of chlorophyll to leaf $\mathrm{N}$ was higher in low nitrogen treatment (Figure 2). This suggests that maize tends to invest relatively more N into light harvesting complexes (LHCs), PSI and PSII under nitrogen stress. Chlorophyll fluorescence is frequently used to monitor the responses of the photosynthetic apparatus to environmental stressors [8,25] including temperature [26], nitrogen [16] and drought [27]. In our study, all of the chlorophyll fluorescence parameters were affected by nitrogen supply. The ETR was $68 \%$ lower in low nitrogen treatment compared with high nitrogen treatment (Figure 6b), suggesting that low nitrogen impairs electron transport systems. Nitrogen stress reduced by $6.6 \%$ in $\mathrm{Fv} / F \mathrm{~m}$ and $20.4 \%$ in $\mathrm{Fv}^{\prime} / \mathrm{Fm}^{\prime}$ (Figure $6 \mathrm{a}$ ), suggesting that an energy dissipation exists in low nitrogen plants [28]. Light energy absorbed by chlorophyll in a leaf has three fates: it can be used to drive photosynthesis (photochemistry), excess energy can be dissipated as heat, or it can be re-emitted as light-chlorophyll fluorescence [8]. The fraction of light absorbed in PSII that is dissipated thermally $\left(\mathrm{D}=1-F \mathrm{v}^{\prime} / F \mathrm{~m}^{\prime}\right)$ was $18.3 \%$ higher in low nitrogen plants than in high nitrogen plants (Figure 6d). Accordingly, nitrogen-deficient plants had a higher non-photochemical quenching $(q N)$ in low nitrogen treatment (Figure 6c) $[9,16]$. The fraction of light absorbed in PSII that is utilized in PSII photochemistry could be represented by $\Phi_{\text {PSII }}$. $\Phi_{\text {PSII }}$ was $67.4 \%$ lower in low nitrogen plants compared with in high nitrogen plants. Nitrogen-deficient plants had a lower photochemical quenching $(q P)$ in low nitrogen treatment (Figure 6c). Lower $q P$ means a lower degree of open PSII, resulting in lower $\Phi_{\mathrm{PSII}}$. The fraction of light absorbed in PSII that is dissipated in chlorophyll fluorescence $\left(F \mathrm{v}^{\prime} / F \mathrm{~m} \cdot{ }^{*}(1-q P)\right)$ is increased by $10.3 \%$ in low nitrogen plants compared with high nitrogen plants (Figure 6d). Thus, it is supposed that low nitrogen impaired PSII, as well as electron transport. Excess energy can be dissipated thermally or re-emitted as light-chlorophyll fluorescence. In accordance, RNA-Seq analysis found that about 27 DEGs encoding PSII systems, and 13 DEGs encoding PSI systems, were downregulated by low nitrogen supply (Figure 5). Among these downregulated DEGs, GRMZM2G351977, GRMZM2G414192, GRMZM2G149428 and GRMZM2G092427 encoded Lhcb1, $L h c b 2, L h c b 5$, and $L h c b 6$, respectively. Six different proteins comprise the antenna system of PSII: three minor proteins (CP29, CP26 and CP24) encoded by Lhcb4, Lhcb5 and Lhcb6; and the major complex LHCII, which consists of three proteins encoded by $L h c b 1$, Lhcb2 and $L h c b 3$, of which the $L h c b 1$ and $L h c b 2$ proteins are by far the most abundant [29]. In antisense plants of Arabidopsis thaliana, there is an absence of the $L h c b 1$ and $L h c b 2$ proteins, accompanied by reduced light absorption [29]. In Arabidopsis thaliana, mutant lines of $L h c b 5$ and $L h c b 6$ have a decreased efficiency of energy transfer from LHCII to the reaction center of PSII [30]. In addition, Lhcb6 absence limits plastoquinone diffusion, and thus inhibits the electron transport rate [30]. Thus, lower expression of GRMZM2G351977, GRMZM2G414192, GRMZM2G149428 and GRMZM2G092427 resulted in lower synthesis of Lhcb1, Lhcb2, Lhcb5, and Lhcb6, respectively. Reduced expression of these genes also resulted in limited light absorption, light transport and electron transport. This is consistent with the results of chlorophyll fluorescence. 
GRMZM2G038519 and GRMZM2G072280 encoded Lhca1 and Lhca2, respectively. The antenna systems of PSI exist as Lhca1/4 and Lhca2/3 dimers. The absence of one antenna complex leaves a "hole" in the structure that cannot be filled by other Lhca proteins [31]. Therefore, lower expression of GRMZM2G038519 and GRMZM2G072280 resulted in lower synthesis of antenna systems of PSI, thus reducing light absorption in low nitrogen stress.

Overapplication of nitrogen has been a common problem in China, resulting in low $\mathrm{N}$ use efficiency (NUE) and environmental pollution [32]. NUE can be improved by precision nitrogen management and nitrogen-efficient cultivars. For both approaches, it is necessary to diagnose plant nitrogen nutrition status timely and precisely. Chlorophyll fluorescence has been used to estimate plant nitrogen status [33]. The findings of this research suggest that chlorophyll fluorescence and the related genes could potentially be explored for developing new tools for the diagnosis of plant nutrition status. Based on the chlorophyll fluorescence parameters, and the differentially expressed genes in response to nitrogen deficiency, nitrogen-efficient genotypes could be discerned at the early seedling stage. Nitrogen deficiency could be detected at the early seedling stage so that nitrogen application recommendation can be made in a timely manner. Indeed, in potatoes, it was found that chlorophyll fluorescence can discriminate between genotypes, predict plant age, and yield performance under field conditions [34].

In conclusion, our results show that low nitrogen supply results in the downregulation of key genes involved in light reactions of photosynthesis. Of particular importance are PSI and PSII genes including GRMZM2G351977, GRMZM2G414192, GRMZM2G149428, GRMZM2G092427, GRMZM2G038519 and GRMZM2G072280. Downregulated expression of those genes resulted in reduced light absorption and light transport. As a result, the parameters relating to chlorophyll fluorescence $\left(\Phi_{\mathrm{PSII}}\right.$, electron transport rate, $\left.q P\right)$ were lower, which contributed to a lower photosynthetic rate. These findings suggest the potential to utilize chlorophyll fluorescence parameters, as well as the related genes, as indicators of plant nitrogen nutrition. In addition, this could be used to develop new tools to make precise nitrogen fertilizer recommendations, and select nitrogen-efficient genotypes.

\section{Materials and Methods}

\subsection{Plant Material and Growth Condition}

Seeds of maize (Zea mays L.) inbred line $\mathrm{B} 73$ were sterilized in $10 \%(v / v) \mathrm{H}_{2} \mathrm{O}_{2}$ for 30 min, washed with distilled water, and then soaked in saturated $\mathrm{CaSO}_{4}$ solution for $8 \mathrm{~h}$. Then, the seeds were washed and placed between sheets of filter paper and germinated in the dark at room temperature. When the roots were approximately $1 \mathrm{~cm}$ long, uniform seedlings were wrapped in filter paper and transferred into a plastic container filled with distilled water. The seedlings with two visible leaves were then transferred into porcelain pots (4 seedlings per pot) containing $2 \mathrm{~L}$ of nutrient solution after the endosperm was removed. The plants were grown in a growth chamber at $28 / 22{ }^{\circ} \mathrm{C}$ with a $14 / 10 \mathrm{~h} \mathrm{light/dark} \mathrm{cycle.} \mathrm{During} \mathrm{the} \mathrm{light} \mathrm{cycle,} \mathrm{the} \mathrm{photosynthetic} \mathrm{photon} \mathrm{flux} \mathrm{density} \mathrm{was}$ 250-300 $\mu \mathrm{mol} \cdot \mathrm{m}^{-2} \cdot \mathrm{s}^{-1}$ at canopy height.

The nutrient solution contained $0.75 \mathrm{mM} \mathrm{K}_{2} \mathrm{SO}_{4}, 0.1 \mathrm{mM} \mathrm{KCl}, 0.25 \mathrm{mM} \mathrm{KH}_{2} \mathrm{PO}_{4}, 0.65 \mathrm{mM} \mathrm{MgSO}_{4}$ ， $0.13 \mathrm{mM}$ Ethylenediaminetetraacetic acid (EDTA)-Fe, $1.0 \mu \mathrm{M} \mathrm{MnSO}_{4}, 1.0 \mu \mathrm{M} \mathrm{ZnSO}_{4}, 0.1 \mu \mathrm{M} \mathrm{CuSO}_{4}$ and $0.005 \mu \mathrm{M}\left(\mathrm{NH}_{4}\right)_{6} \mathrm{Mo}_{7} \mathrm{O}_{24}$ [35]. Plants were supplied with half-strength nutrient solution containing $4.0 \mathrm{mM} \mathrm{NO}_{3}$ (provided as $\left.\mathrm{Ca}\left(\mathrm{NO}_{3}\right)_{2}\right)$ for 2 days, and then transferred into full-strength solution with $4.0 \mathrm{mM} \mathrm{NO}_{3}$ (high nitrogen). When the third leaf was fully expanded (approximately 6 days later), half of the plants were moved into a solution with $40 \mu \mathrm{M} \mathrm{NO}_{3}$ (low nitrogen), with $\mathrm{CaCl}_{2}$ added to equalize calcium concentration between the treatments. The $\mathrm{pH}$ of the solution was adjusted to 5.8-6.0 with $\mathrm{KOH}$. The solution was renewed every other day and was aerated continuously by a pump. The pots were arbitrarily placed and rotated when the nutrient solution was renewed. 


\subsection{Plant Weight, Leaf Area, and Photosynthesis}

When the sixth leaf was fully expanded, plants were harvested and separated into root, leaf 6 , and shoot (other leaves plus stems). The length and width of the leaves were measured with a ruler. Half of sixth leaves were stored at $-80^{\circ} \mathrm{C}$. Other samples were dried in an oven at $70{ }^{\circ} \mathrm{C}$. Dried samples were weighed and ground to a powder and the nitrogen concentration was determined by an elemental analyzer (vario MACRO, Elementar, Langenselbold, Germany).

The sixth expanded leaf from 16 plants of each nitrogen treatment was used to measure the net photosynthetic rate by LI6400 (LI-COR, Lincoln, NE, USA) at a light density of $800 \mu \mathrm{mol} \cdot \mathrm{m}^{-2} \cdot \mathrm{s}^{-1}$ [5]. The $\mathrm{CO}_{2}$ concentration inside the chamber was controlled at $400 \pm 1 \mu \mathrm{mol}$ $\mathrm{CO}_{2}(\mathrm{~mol} \text { air })^{-1}$. Chlorophyll (Chl) was extracted using acetone and ethanol, and the absorbance of extracts was spectrophotometrically measured at 645 and $663 \mathrm{~nm}$ [36].

\subsection{Chlorophyll Fluorescence}

Chlorophyll fluorescence was measured with an integrating fluorescence fluorometer (LI-6400, Leaf chamber fluorometer, LI-COR, Lincoln, NE, USA). The fluorescence instable state $(F s)$, maximum fluorescence under light $\left(F \mathrm{~m}^{\prime}\right)$ and minimum fluorescence $\left(F \mathrm{o}^{\prime}\right)$ were measured under light density of $800 \mu \mathrm{mol} \cdot \mathrm{m}^{-2} \cdot \mathrm{s}^{-1}$ and $400 \pm 1 \mu \mathrm{mol} \mathrm{CO}$ (mol air) $^{-1}$. After dark-adaptation of samples for $1 \mathrm{~h}$, the minimal fluorescence $\left(F_{\mathrm{o}}\right)$ and maximum fluorescence $(F \mathrm{~m})$ in darkness were measured. Other fluorescent parameters were calculated as follows [37]: maximal photochemical efficiency $(F \mathrm{v} / F \mathrm{~m}): F \mathrm{v} / F \mathrm{~m}=(F \mathrm{~m}-F \mathrm{o}) / F \mathrm{~m}$; excitation energy capture efficiency of PSII reaction centers $\left(F \mathrm{v}^{\prime} / F \mathrm{~m}^{\prime}\right): F \mathrm{v}^{\prime} / F \mathrm{~m}^{\prime}=\left(F \mathrm{~m}^{\prime}-F \mathrm{o}^{\prime}\right) / F \mathrm{~m}^{\prime} ; \Phi_{\mathrm{PSII}}=\left(F \mathrm{~m}^{\prime}-F \mathrm{~s}\right) / F \mathrm{~m}^{\prime} ; \mathrm{ETR}=\mathrm{PPFD} \times \Phi_{\mathrm{PSII}}$ $\times 0.85 \times 0.5$ (where PPFD is photosynthetic photon flux density); Photochemical quenching $(q P): q P=\left(F \mathrm{~m}^{\prime}-F \mathrm{~s}\right) /\left(F \mathrm{~m}^{\prime}-F \mathrm{o}^{\prime}\right)$; Non-photochemical quenching $(q N): q N=\left(F \mathrm{~m}-F \mathrm{~m}^{\prime}\right) /$ $\left(F \mathrm{~m}-F \mathrm{o}^{\prime}\right)$. The following three derived chlorophyll fluorescence parameters were employed to analyze the allocation of fraction of excitation energy: $\mathrm{D}=1-F \mathrm{v}^{\prime} / F \mathrm{~m}^{\prime}$ is the fraction of photon energy absorbed in PSII and dissipated via thermal energy in the antenna; $\Phi_{\text {PSII }}$ represents the fraction of photon energy absorbed in PSII utilized for photosynthetic electron transport; $E x=F \mathrm{v}^{\prime} / F \mathrm{~m}^{\prime} . *(1-q P)$ is the estimate of the fraction of excess excitation energy re-emitted as light-chlorophyll fluorescence.

\subsection{RNA Library Construction and Illumina Sequencing}

The mature tissue of an expanding leaf was sampled. The samples were frozen in liquid nitrogen and stored at $-80^{\circ} \mathrm{C}$. Total RNA was extracted [38]. Two replicates were used to RNA-Seq. RNA-Seq libraries were prepared according the manufacturer's protocol of the Illumina Standard mRNA-Seq library preparation kit (Illumina, San Diego, CA, USA) and were sequenced to generate 125-nucleotide paired-end reads on an Illumina HiSeq platform (Illumina HisSeq 2500, San Diego, CA, USA).

\subsection{Bioinformatics Analysis of RNA-Seq Data}

Raw reads were pre-processed to remove low quality regions and adapter sequences. At least 30 million clean reads were obtained. Clean reads from each sample were aligned to the maize reference genome (B73 RefGen_v3, available online: http:/ /www.maizegdb.org/assembly /) using TopHat2 [39]. Aligned reads from TopHat2 mapping were subjected to String Tie for DeNovo transcript assembly $[39,40]$. The $R$ package edge $R$ was used to identify the differentially expressed genes [41]. The expression of each gene was normalized to fragments per kilobase of transcript per million reads (FPKM) to compare different samples. Low-level expressed genes were removed and only genes with an expression level of at least 1 FPKM in at least two samples were kept for further analysis. A gene was regarded as differentially expressed if the false discovery rate (FDR) was less than 0.05 , and had a $\log 2$ fold change higher than 1.

The Gene Ontology (GO) term enrichment of differential expressed genes was conducted using the web-based agriGO software (Available online: http:/ / bioinfo.cau.edu.cn/agriGO/analysis.php). 
Singular enrichment analysis (SEA) was used to compute enriched categories by comparing a list of differentially expressed genes to all expressed genes. GO terms of gene sets of interest compared with the genome-wide background with an adjusted $p$ value (FDR) cutoff of 0.01 . MapMan was used to show the functional categorization of differentially expressed genes in different cellular and metabolic processes [42].

Raw sequencing data are stored at the Sequence Read Archive (Available online: http:/ / www. ncbi.nlm.nih.gov/sra) under accession number GSE107562.

\subsection{Statistical Analysis}

Data were subjected to variance analysis using ANOVA procedure implemented in SPSS Statistics 19.0 (SPSS, Inc., Chicago, IL, USA). Differences were compared using the least significant difference test at 0.05 level of probability.

Supplementary Materials: Supplementary materials can be found at www.mdpi.com/1422-0067/18/12/2624/s1.

Acknowledgments: We gratefully acknowledge the financial support of the National Science Foundation of China (No. 21022182).

Author Contributions: Xiaohuan Mu performed the experiments, analyzed the samples, and drafted the manuscript; Qinwu Chen helped in performing experiments and analyzing data; Fanjun Chen provided material and contributed to the experimental design; Lixing Yuan supervised and assisted with writing; Guohua Mi conceived of the original screening and research plans, and revised the manuscript.

Conflicts of Interest: The authors declare no conflict of interest.

\section{References}

1. Chen, Q.; Mu, X.; Chen, F.; Yuan, L.; Mi, G. Dynamic change of mineral nutrient content in different plant organs during the grain filling stage in maize grown under contrasting nitrogen supply. Eur. J. Agron. 2016, 80, 137-153. [CrossRef]

2. Chen, Y.; Xiao, C.; Wu, D.; Xia, T.; Chen, Q.; Chen, F.; Yuan, L.; Mi, G. Effects of nitrogen application rate on grain yield and grain nitrogen concentration in two maize hybrids with contrasting nitrogen remobilization efficiency. Eur. J. Agron. 2015, 62, 79-89. [CrossRef]

3. Uribelarrea, M.; Crafts-Brandner, S.J.; Below, F.E. Physiological N response of field-grown maize hybrids (Zea mays L.) with divergent yield potential and grain protein concentration. Plant Soil 2009, 316, 151. [CrossRef]

4. Vos, J.; Van der Putten, P.; Birch, C. Effect of nitrogen supply on leaf appearance, leaf growth, leaf nitrogen economy and photosynthetic capacity in maize (Zea mays L.). Field Crop Res. 2005, 93, 64-73. [CrossRef]

5. $\mathrm{Mu}, \mathrm{X}$.; Chen, Q.; Chen, F.; Yuan, L.; Mi, G. Within-leaf nitrogen allocation in adaptation to low nitrogen supply in maize during grain-filling stage. Front. Plant Sci. 2016, 7, 699. [CrossRef] [PubMed]

6. Hawkesford, M.J.; Barraclough, P. The Molecular and Physiological Basis of Nutrient Use Efficiency in Crops; John Wiley \& Sons: Hoboken, NJ, USA, 2011.

7. Blankenship, R.E. Molecular Mechanisms of Photosynthesis; John Wiley \& Sons: Hoboken, NJ, USA, 2013.

8. Maxwell, K.; Johnson, G.N. Chlorophyll fluorescence-A practical guide. J. Exp. Bot. 2000, 51, 659-668. [CrossRef] [PubMed]

9. Huang, Z.-A.; Jiang, D.-A.; Yang, Y.; Sun, J.-W.; Jin, S.-H. Effects of nitrogen deficiency on gas exchange, chlorophyll fluorescence, and antioxidant enzymes in leaves of rice plants. Photosynthetica 2004, 42, 357-364. [CrossRef]

10. Zhao, D.; Reddy, K.R.; Kakani, V.G.; Reddy, V. Nitrogen deficiency effects on plant growth, leaf photosynthesis, and hyperspectral reflectance properties of sorghum. Eur. J. Agron. 2005, 22, 391-403. [CrossRef]

11. Ghannoum, O.; Evans, J.R.; Chow, W.S.; Andrews, T.J; Conroy, J.P.; von Caemmerer, S. Faster Rubisco is the key to superior nitrogen-use efficiency in NADP-malic enzyme relative to NAD-malic enzyme $\mathrm{C}_{4}$ grasses. Plant Physiol. 2005, 137, 638-650. [CrossRef] [PubMed]

12. Ding, L.; Wang, K.; Jiang, G.; Biswas, D.; Xu, H.; Li, L.; Li, Y. Effects of nitrogen deficiency on photosynthetic traits of maize hybrids released in different years. Ann. Bot. 2005, 96, 925-930. [CrossRef] [PubMed] 
13. Poorter, H.; Evans, J.R. Photosynthetic nitrogen-use efficiency of species that differ inherently in specific leaf area. Oecologia 1998, 116, 26-37. [CrossRef] [PubMed]

14. Makino, A.; Shimada, T.; Takumi, S.; Kaneko, K.; Matsuoka, M.; Shimamoto, K.; Nakano, H.; Miyao-Tokutomi, M.; Mae, T.; Yamamoto, N. Does decrease in ribulose-1,5-bisphosphate carboxylase by antisense $\mathrm{RbcS}$ lead to a higher $\mathrm{N}$-use efficiency of photosynthesis under conditions of saturating $\mathrm{CO}_{2}$ and light in rice plants? Plant Physiol. 1997, 114, 483-491. [CrossRef] [PubMed]

15. Ciompi, S.; Gentili, E.; Guidi, L.; Soldatini, G.F. The effect of nitrogen deficiency on leaf gas exchange and chlorophyll fluorescence parameters in sunflower. Plant Sci. 1996, 118, 177-184. [CrossRef]

16. Lu, C.; Zhang, J. Photosynthetic $\mathrm{CO}_{2}$ assimilation, chlorophyll fluorescence and photoinhibition as affected by nitrogen deficiency in maize plants. Plant Sci. 2000, 151, 135-143. [CrossRef]

17. Evans, J.R. Improving photosynthesis. Plant Physiol. 2013, 162, 1780-1793. [CrossRef] [PubMed]

18. Ort, D.R.; Merchant, S.S.; Alric, J.; Barkan, A.; Blankenship, R.E.; Bock, R.; Croce, R.; Hanson, M.R.; Hibberd, J.M.; Long, S.P. Redesigning photosynthesis to sustainably meet global food and bioenergy demand. Proc. Natl. Acad. Sci. USA 2015, 112, 8529-8536. [CrossRef] [PubMed]

19. Paponov, I.; Sambo, P.; Presterl, T.; Geiger, H.; Engels, C. Grain yield and kernel weight of two maize genotypes differing in nitrogen use efficiency at various levels of nitrogen and carbohydrate availability during flowering and grain filling. Plant Soil 2005, 272, 111-123. [CrossRef]

20. Muchow, R.; Sinclair, T. Nitrogen response of leaf photosynthesis and canopy radiation use efficiency in field-grown maize and sorghum. Crop Sci. 1994, 34, 721-727. [CrossRef]

21. McCullough, D.; Aguilera, A.; Tollenaar, M. N uptake, N partitioning, and photosynthetic N-use efficiency of an old and a new maize hybrid. Can. J. Plant Sci. 1994, 74, 479-484. [CrossRef]

22. Albertsson, P.-Å.; Andreasson, E.; Svensson, P. The domain organization of the plant thylakoid membrane. FEBS Lett. 1990, 273, 36-40. [CrossRef]

23. Ballottari, M.; Girardon, J.; Betterle, N.; Morosinotto, T.; Bassi, R. Identification of the chromophores involved in aggregation-dependent energy quenching of the monomeric photosystem II antenna protein Lhcb5. J. Biol. Chem. 2010, 285, 28309-28321. [CrossRef] [PubMed]

24. Kitaoka, S.; Koike, T. Invasion of broad-leaf tree species into a larch plantation: Seasonal light environment, photosynthesis and nitrogen allocation. Physiol. Plant. 2004, 121, 604-611. [CrossRef]

25. Krause, G.; Weis, E. Chlorophyll fluorescence and photosynthesis: The basics. Annu. Rev. Plant Biol. 1991, 42, 313-349. [CrossRef]

26. Pastenes, C.; Horton, P. Effect of high temperature on photosynthesis in beans (I. Oxygen evolution and chlorophyll fluorescence). Plant Physiol. 1996, 112, 1245-1251. [CrossRef] [PubMed]

27. Woo, N.S.; Badger, M.R.; Pogson, B.J. A rapid, non-invasive procedure for quantitative assessment of drought survival using chlorophyll fluorescence. Plant Methods 2008, 4, 27. [CrossRef] [PubMed]

28. Lu, C.; Lu, Q.; Zhang, J.; Kuang, T. Characterization of photosynthetic pigment composition, photosystem II photochemistry and thermal energy dissipation during leaf senescence of wheat plants grown in the field. J. Exp. Bot. 2001, 52, 1805-1810. [CrossRef] [PubMed]

29. Jenny, A.; Mark, W.; Robin, G.; Caroline, A.; Alexander, V.; Peter, H.; Stefan, J. Absence of the Lhcb1 and Lhcb2 proteins of the light-harvesting complex of photosystem II-Effects on photosynthesis, grana stacking and fitness. Plant J. 2003, 35, 350-361. [CrossRef]

30. De Bianchi, S.; Dall'Osto, L.; Tognon, G.; Morosinotto, T.; Bassi, R. Minor antenna proteins CP24 and CP26 affect the interactions between photosystem II subunits and the electron transport rate in grana membranes of Arabidopsis. Plant Cell 2008, 20, 1012-1028. [CrossRef] [PubMed]

31. Wientjes, E.; Oostergetel, G.T.; Jansson, S.; Boekema, E.J.; Croce, R. The role of Lhca complexes in the supramolecular organization of higher plant photosystem I. J. Biol. Chem. 2009, 284, 7803-7810. [CrossRef] [PubMed]

32. Miao, Y.; Stewart, B.A.; Zhang, F. Long-term experiments for sustainable nutrient management in China. A review. Agron. Sustain. Dev. 2011, 31, 397-414. [CrossRef]

33. Ziadi, N.; Brassard, M.; Bélanger, G.; Claessens, A.; Tremblay, N.; Cambouris, A.N.; Nolin, M.C.; Parent, L.-É. Chlorophyll measurements and nitrogen nutrition index for the evaluation of corn nitrogen status. Agron. J. 2008, 100, 1264-1273. [CrossRef] 
34. Živčák, M.; Olšovská, K.; Slamka, P.; Galambošová, J.; Rataj, V.; Shao, H.; Brestič, M. Application of chlorophyll fluorescence performance indices to assess the wheat photosynthetic functions influenced by nitrogen deficiency. Plant Soil Environ. 2014, 60, 210-215.

35. Gao, K.; Chen, F.; Yuan, L.; Zhang, F.; Mi, G. A comprehensive analysis of root morphological changes and nitrogen allocation in maize in response to low nitrogen stress. Plant Cell Environ. 2015, 38, 740-750. [CrossRef] [PubMed]

36. Porra, R.; Thompson, W.; Kriedemann, P. Determination of accurate extinction coefficients and simultaneous equations for assaying chlorophylls $a$ and $b$ extracted with four different solvents: Verification of the concentration of chlorophyll standards by atomic absorption spectroscopy. BBA-Bioenergetics 1989, 975, 384-394. [CrossRef]

37. Genty, B.; Briantais, J.-M.; Baker, N.R. The relationship between the quantum yield of photosynthetic electron transport and quenching of chlorophyll fluorescence. BBA-General Subj. 1989, 990, 87-92. [CrossRef]

38. Gu, R.; Duan, F.; An, X.; Zhang, F.; von Wirén, N.; Yuan, L. Characterization of AMT-mediated high-affinity ammonium uptake in roots of maize (Zea mays L.). Plant Cell Physiol. 2013, 54, 1515-1524. [CrossRef] [PubMed]

39. Kim, D.; Pertea, G.; Trapnell, C.; Pimentel, H.; Kelley, R.; Salzberg, S.L. TopHat2: Accurate alignment of transcriptomes in the presence of insertions, deletions and gene fusions. Genome Biol. 2013, 14, R36. [CrossRef] [PubMed]

40. Pertea, M.; Pertea, G.M.; Antonescu, C.M.; Chang, T.-C.; Mendell, J.T.; Salzberg, S.L. StringTie enables improved reconstruction of a transcriptome from RNA-seq reads. Nat. Biotechnol. 2015, 33, 290-295. [CrossRef] [PubMed]

41. Robinson, M.D.; McCarthy, D.J.; Smyth, G.K. edgeR: A Bioconductor package for differential expression analysis of digital gene expression data. Bioinformatics 2010, 26, 139-140. [CrossRef] [PubMed]

42. Thimm, O.; Bläsing, O.; Gibon, Y.; Nagel, A.; Meyer, S.; Krüger, P.; Selbig, J.; Müller, L.A.; Rhee, S.Y.; Stitt, M. MAPMAN: A user-driven tool to display genomics data sets onto diagrams of metabolic pathways and other biological processes. Plant J. 2004, 37, 914-939. [CrossRef] [PubMed]

(C) 2017 by the authors. Licensee MDPI, Basel, Switzerland. This article is an open access article distributed under the terms and conditions of the Creative Commons Attribution (CC BY) license (http:/ / creativecommons.org/licenses/by/4.0/). 